\title{
Postoperative radiotherapy for pediatric brain tumor: a lesson learned from treatment of a 5-year-old girl for posterior fossa astrocytoma (WHO1) in 1967
}

\author{
Tryggve Lundar ${ }^{1,2}$ (D) $\cdot$ Bernt Johan Due-Tønnessen ${ }^{1} \cdot$ Radek Fric $^{1} \cdot$ Paulina Due-Tønnessen $^{3}$
}

Received: 6 June 2018 / Accepted: 19 July 2018 / Published online: 26 July 2018

(C) The Author(s) 2018

Dear Editor,

We have for many years followed a patient whose long-term history illustrates how therapeutic decisions for benign lesions can affect and determine the entire life of a patient.

In 1967, a 5-year-old girl presented with progressive headache, vomiting, and ataxia. Clinical examination disclosed papilledema. Ventriculography demonstrated supratentorial hydrocephalus and lack of contrast passage to the fourth ventricle indicating a posterior fossa tumor. She underwent resection of a large, partially cystic tumor. Postoperatively, there was a right-sided hypacusis and slight persistent ataxia.

The histological examination showed astrocytoma WHO1. The resection was considered incomplete and she was given postoperative radiotherapy to the posterior fossa. Two posterior fossa fields were given small doses over 15 days up to $2750 \mathrm{r}$ in each field.

She recovered and after a couple of years, someone asked: "why did you give XRT?"

The answer was: "It was not much-only $2750 \mathrm{r} \times 2$ ".

Fourteen years later, in 1981, she once more presented with clinical symptoms and signs of intracranial hypertension. A

This article is part of the Topical Collection on Pediatric Neurosurgery

Tryggve Lundar

tryggve.lundar@gmail.com; tryggve.lundar@ous-hf.no

1 Department of Neurosurgery, Oslo University Hospital, Oslo, Norway

2 Faculty of Medicine, Institute of Clinical Medicine, University of Oslo, Oslo, Norway

3 Department of Radiology, Oslo University Hospital, Oslo, Norway
CT scan revealed a large cystic expansion in the posterior fossa along with supratentorial hydrocephalus. After a second operation with opening of the cyst and subtotal tumor resection, the histology was once more astrocytoma grade WHO1. After this second procedure, she once more recovered, but experienced right-sided anacusis and over time progressive left-sided hypacusis as well.

During the late 1990s, she deteriorated and MRI now disclosed large supratentorial meningioma formations. The tumor was resected along with the right side of the tentorium in 2000. Two years later, in 2002, she needed resection of a large meningioma in the sellar region and she was given hormonal substitution. During the following years, she lost her vision over time and underwent repeat tumor resections for aggressive malignant meningiomas in the years 2004 and 2006.

The clinical condition deteriorated further and she was bedridden, deaf, and blind during the rest of life, until she passed away in 2016. Follow-up MRI in 2011 demonstrated further intracranial meningioma progression (Fig. 1), but additional operative treatment was not found useful and she was given only palliative care until she died in 2016.

Fifty years ago, postoperative radiotherapy in the treatment of posterior fossa medulloblastoma dramatically improved the 5 -year survival rates from zero to more than $50 \%$ [3]. In children with low-grade posterior fossa astrocytoma, such treatment has never been standard but has been given in selected cases. The decision for radiotherapy appears to be incomplete resection or such treatment is applied after a second resection or instead of repeat surgery [2].

Although our policy has been repeat surgery when indicated instead of adjuvant radiotherapy, a few patients have been given such adjuvant postoperative radiotherapy up to the late 1980s [1]. It is difficult to delineate the 
Fig. 1 Sagittal MRI showing meningioma along the falx cerebri and the sella region, but no residual tumor in the posterior fossa (2011)

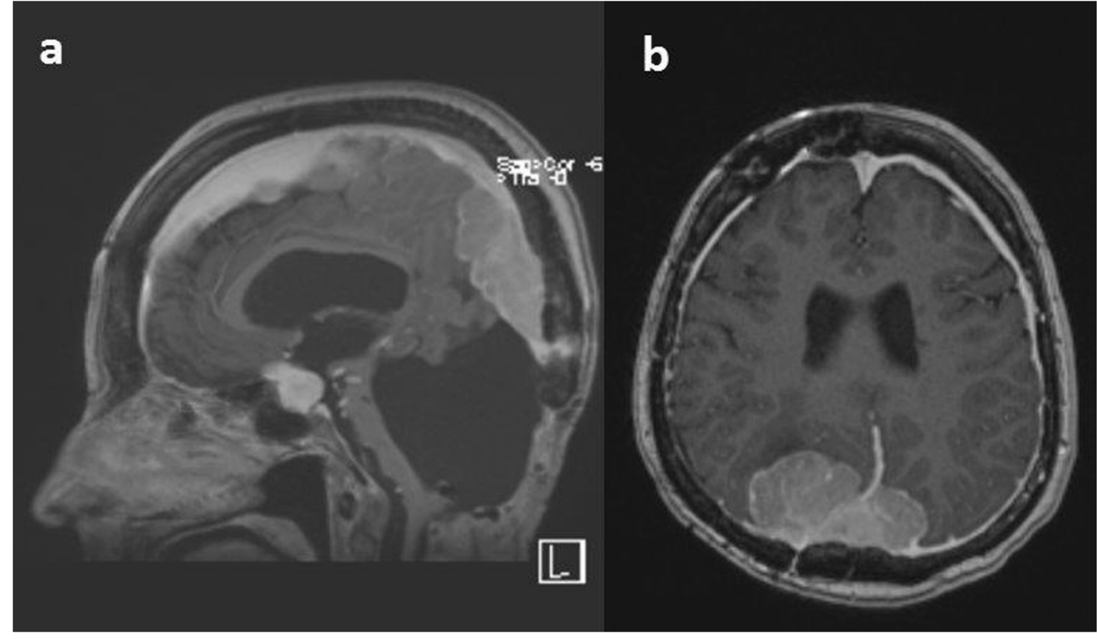

precise reason for the decision. It may reflect differences in opinion among the individual members in the team when treatment after incomplete resection was discussed. This case reminds us that a simple therapeutic decision which was apparently taken lightly had serious consequences for this patient.

The present case is - in our opinion - a kind of the worst possible result-a progressive disaster over nearly five decades.

\section{Compliance with ethical standards}

Conflict of interest The authors declare that they have no conflict of interest.

Open Access This article is distributed under the terms of the Creative Commons Attribution 4.0 International License (http:// creativecommons.org/licenses/by/4.0/), which permits unrestricted use, distribution, and reproduction in any medium, provided you give appropriate credit to the original author(s) and the source, provide a link to the Creative Commons license, and indicate if changes were made.

\section{References}

1. Due-Tønnessen BJ, Lundar T, Egge A, Scheie D (2013) Neurosurgical treatment of low-grade cerebellar astrocytoma in children and adolescents: a single consecutive institutional series of 100 patients. J Neurosurg Pediatr 11:245-249

2. Saunders DE, Phipps KP, Wade AM, Hayward RD (2005) Surveillance imaging strategies following surgery and/or radiotherapy for childhood cerebellar low-grade astrocytoma. J Neurosurg 102(2 Suppl):172-178

3. Stensvold E, Krossnes BK, Lundar T, Due-Tønnessen BJ, Fric R, Due-Tønnessen P, Bechensteen AG, Myklebost TÅ, Johannesen TB, Brandal P (2017) Outcome for children treated for medulloblastoma and supratentorial primitive neuroectodermal tumor (CNS-PNET) a retrospective analysis spanning 40 years of treatment. Acta Oncol $56: 698-705$ 